\title{
(2) OPEN ACCESS \\ Analysis of submissions to the EU's public consultation on tobacco traceability and security features
}

\author{
Allen William Andrew Gallagher ํㅏ, ${ }^{1}$ Karen Evans-Reeves ํㅏ, ${ }^{1}$ Ayush Joshi, \\ Jenny Hatchard, ${ }^{2}$ Anna B Gilmore ${ }^{1}$
}

- Additional material is published online only. To view, please visit the journal online (http://dx.doi.org/10.1136/ tobaccocontrol-2020-043875)

${ }^{1}$ Tobacco Control Research Group, Department for Health, University of Bath, Bath, UK ${ }^{2}$ Bristol Medical School, University of Bristol, Bristo United Kingdom

\section{Correspondence to} Allen William Andrew Gallagher, Department for Health, University of Bath, Bath, UK a.a.gallagher@bath.ac.uk

Received 28 April 2020 Revised 10 August 2020 Accepted 11 August 2020
Check for updates

(c) Author(s) (or their employer(s)) 2020. Re-use permitted under CC BY-NC. No commercial re-use. See rights and permissions. Published by BMJ.

To cite: Gallagher AWA, Evans-Reeves K, Joshi A, et al Tob Control Epub ahead of print: [please include Day Month Year]. doi:10.1136/ tobaccocontrol-2020-043875

\section{ABSTRACT}

Background The Protocol to Eliminate Illicit Trade in Tobacco Products requires all parties to establish a tobacco track and trace (T\&T) system. In 2016, the European Commission held a public consultation on T\&T implementation where parties were asked to respond online to 22 multiple-choice questions and were given additional opportunities to leave comments. In May 2019, the European Union's (EU) T\&T system became operational. This paper explores tobacco industry influence over and policy positions within the consultation process.

Methods We identified consultation respondents and investigated any financial links with the tobacco industry and if these were transparent. Respondent's answers to the consultation's multiple-choice questions were collated to explore whether industry-linked respondents held the same policy positions as transnational tobacco companies (TTCS). Associations between policy positions and respondent's financial link status were tested using $\chi^{2}$ and Cranmer's $V$ tests.

Findings Of the 197 consultation respondents identified, $131(66.4 \%)$ had financial links to the industry; 29 (22.1\%) were not transparent about these links. A large number of trade associations responded (87), the majority of which (74/87) had financial links to the industry. There was a clear divide in the policy preferences of respondents with and without a financial link. Collectively, respondents with a financial link supported an industry-operated T\&T solution.

Conclusions There was an extensive lobbying effort by the tobacco industry over the EU's T\&T system, with TTCs' interests being represented repeatedly through multiple trade associations. The transparency requirements regarding consultation respondents' affiliations with relevant stakeholders (eg, tobacco manufacturers) should be improved for future consultations.

\section{INTRODUCTION}

Article 8 of the Protocol to Eliminate Illicit Trade in Tobacco Products (hereby referred to as 'the Protocol') requires each party to the Protocol to establish its own tracking and tracing (T\&T) system with the aim of creating a global regime for T\&T tobacco products. ${ }^{1}$ T\&T is a means of supply chain control where tobacco products are tracked through their distribution chain and, should they enter the illicit market, 'traced' back to determine where in the supply chain this happened. The Protocol's T\&T requirements are a response to extensive evidence of transnational tobacco company (TTC) involvement in illicit trade (including complicity in tobacco smuggling). ${ }^{2-11}$

On 20 May 2019, following a 6-year process by the European Commission to develop and implement a T\&T system, one was introduced in the European Union (EU). ${ }^{12}$ This process involved a public consultation, which ran from July to November $2016^{13}$ (see online supplemental appendix 1 for further details on the EU's T\&T implementation process).

The EU is the largest example of tobacco T\&T implementation in the world, and this consultation, to our knowledge, was the first ever on T\&T where responses are publicly available.

The consultation featured 28 questions, covering five distinct issues involving the development of an EU-wide T\&T system. Twenty-two of the questions were multiple choice, with the other six providing respondents with a comment box to add additional information if they so desired. Depending on a respondent's answers to each question, subquestions may appear asking them to provide their reasoning for a specific response in an additional comment box (table 1).

While the Tobacco Products Directive emphasised that, to meet the Framework Convention on Tobacco Control's (FCTC) requirements, the EU's T\&T system should be transparent and ensure independence from the industry, ${ }^{14}$ concerns over the extent to which the EU's T\&T system meets these standards have been raised. Several members of the European Parliament, ${ }^{15-17}$ academics and non-governmental organisations ${ }^{16} 1819$ have indicated that the EU's T\&T may be in conflict with the Protocol.

The overarching concern is that the system has a 'mixed' governance, with the tobacco industry having key responsibilities including delegating the tasks of choosing data storage providers and auditors to manufacturers and importers of tobacco products. $^{20}$ It should be noted however that the European Commission does have complete oversight over the data repositories and thus the ability to reject any of the industry's selections.

Nonetheless, concerns around the independence of the system led to the International Tax Stamp Association (ITSA) filing a case against the European Commission claiming that the governance of the system breaches the Protocol. ${ }^{18} 21$ This was dismissed by the EU Court of Justice in May 2019, with ITSA filing an appeal in July 2019. ${ }^{22}$ 
Table 1 Structure of the key content of the 2016 public consultation on the EU's track and trace system

Q1-6 Five multiple-choice questions on the potential governance model of the system and a question asking for any relevant comments or suggestions.

Q7-12 Five multiple-choice questions on where data collected from the system should be stored and a question asking for any relevant comments or suggestions.

Q13-16 Three multiple-choice questions on what the barcode/s (referred to in the consultation as data carriers) used for the system should be and a question asking for any relevant comments or suggestions.

Q17-22 Five multiple-choice questions on how much of a delay in the reporting of supply chain events should be permitted and a question asking for any relevant comments or suggestions.

Q23-27 Four multiple-choice questions on how security features (eg, holograms, microprint and molecular tags) should be added to product packaging and a question asking for any relevant comments or suggestions.

Q28 A final question inviting respondents to upload any supplementary material for their submission.

Additionally, the Framework Convention Alliance (FCA), a confederation of organisations focused on supporting FCTC implementation, expressed similar concerns in August 2019 over the EU's T\&T system's potential lack of compliance with the Protocol. ${ }^{19}$ In October 2019, the European Commission responded to these concerns, arguing that the EU's T\&T system 'fully complies' with the Protocol, with the FCA later reaffirming its view that the EU system's delegation of tasks to the tobacco industry conflicts with the Protocol's requirements. ${ }^{23}$

Such concerns around the EU's T\&T system's compliance with the Protocol are furthered by evidence of TTC influence over the implementation process in the EU and beyond. In 2017, TTCs had monthly meetings with a third party, Inexto, with the minutes of these meetings suggesting Inexto had an ongoing financial relationship with the tobacco industry. The meeting minutes outlined how Inexto engaged with EU Member States and promoted industry-favoured technical standards in the lead up to the final regulations being released..$^{20}$ Industry attempts to influence T\&T have also been documented in national (eg, Kenya) and international contexts. ${ }^{11}$ Such efforts may reflect the potential impact that an effective T\&T system would likely have on TTCs, namely, them having to make increased tax payments if they do not adequately control their own supply chains. This is not an unlikely outcome given that recent evidence shows that the majority of the illicit tobacco trade at UK, EU and global levels consists of products from TTC supply chains. ${ }^{11}$

Given the concerns around tobacco industry interference in EU T\&T implementation and the suggestions that this interference has led to the system potentially being in breach of the Protocol, a deeper understanding of the tobacco industry's role in the EU T\&T policy process is needed. Furthermore, given growing evidence of the tobacco industry using third parties to gain influence both in relation to $T \& \mathrm{~T}^{1120}$ and tobacco policy more broadly, ${ }^{24} 25$ there is a need to better understand how that influence happens. Therefore, this paper investigates the tobacco industry's involvement in the consultation phase of the EU T\&T system's policy progression, providing valuable insight into tobacco industry policy preferences in relation to T\&T.

\section{METHODS}

\section{Data collection}

For the first stage of data collection, all submissions to the European Commission's public consultation on the implementation of an EU system for traceability and security features pursuant to
Articles 15 and 16 of the Tobacco Products Directive 2014/40/ $\mathrm{EU}^{13}$ were downloaded from the EU website. ${ }^{26}$ One hundred and ninety-seven submissions were then featured in the analysis. This is less than the 351 listed on the EU website ${ }^{13}$ for several reasons. First, for this analysis, all anonymous responses and responses from members of the public were removed. Second, the European Commission website collated responses based on respondent's self-reported grouping (eg, retailer and manufacturer) and acknowledged that 'Some respondents indicated that they belong to more than one grouping and in such cases their responses were therefore counted towards each of the groupings indicated by them'. ${ }^{13}$ For example, if a respondent identified as a retailer and another organisation, then their single submission was counted as two, leading to an inflated number of respondents on the website.

For the second stage of data collection, each respondent was coded by sector, using a more detailed framework (see online supplemental appendix 2) than was featured in the consultation checklist. This enabled us to ensure that each respondent was coded into a single sector. The geography of respondents was also coded based on the location of their headquarters as identified in their consultation submissions, or via online searching if respondents did not provide this information. Respondent's financial links to the tobacco industry were then systematically assessed using a process developed from pre-existing research ${ }^{11202728}$ (see online supplemental appendix 3). Given the range of respondents and the various components of the tobacco industry as a whole (eg. manufacturers, wholesalers and distributors), several categories of financial link were defined and included in the coding process (see online supplemental appendix 4). The relative transparency of respondents' financial links was also captured. It is worth noting that even in cases where a financial link between a respondent and the tobacco industry was not identified, this is not proof that a link does not exist.

For the final stage of data collection, the respondent's answers to the 22 multiple-choice questions ('policy positions') within the consultation were collected. Given the large number of responses and the fact that respondents did not always write in English, the six questions as well as subquestions that did not feature multiple-choice options were excluded from this analysis as were any supplementary materials that some respondents provided along with their consultation submissions.

\section{Data analysis}

The data analysis procedure can be separated into four stages. First, to provide an overall picture of respondents and the extent to which the tobacco industry participated in the EU policy debate around T\&T, number and percentage of respondents that were found to have financial links to the tobacco industry both overall and within each of the coded sectors was calculated.

The second stage involved investigation of TTC membership of the trade associations which submitted to the consultation.

Third, each respondent's consultation answers were compared with those of the three TTCs who responded individually to the consultation (Imperial Tobacco, Japan Tobacco International and Philip Morris International) to identify if any respondents provided the same answers as each individual TTC (assessed one at a time) to all of the multiple-choice questions in the consultation. The analysis focuses specifically on the multiple-choice component of the consultation; it does not assess if any complete consultation responses (eg, including additional comments) were identical. 
The fourth and final stage of the analysis explored if there was an association between the policy positions that respondents adopted and respondents' financial link status. It was not possible to do this using logistic regression due to collinearity within the summary scores of each policy topic. As a result, cross-tabulation of individual question answers (polytomous variables, eg, 'yes', 'no' and 'no opinion') with respondent's financial link status (a dichotomous variable, either 'financial link' or 'no financial link') was conducted.

$\chi^{2}$ (a statistical test applied to sets of categorical data to evaluate the likelihood of any observed difference between the sets having arisen by chance) was used for each individual question to test for an association between respondent's answers to each question and their financial link status. Additionally, Cramér's $\mathrm{V}$ test, which is a rescaling of $\chi^{2}$ designed to provide an output between 0 and 1 (the larger the output, the stronger the association), was also conducted for each question. The output of this analysis identifies any statistically significant association between respondent's financial status (either yes or no) and their answers to each question.

\section{RESULTS}

\section{Geography of respondents}

Among all of the respondents, the UK was the most represented country (23) followed by Poland (20), Spain (19) and Germany (17). Countries with the highest number of respondents identified as having financial links to the tobacco industry were Spain (15), Germany (13), Greece and the UK (both 12) (see online supplemental appendix 5 for full list).

\section{Respondents' financial links to the tobacco industry}

One hundred and thirty-one of 197 (66.4\%) respondents to the consultation had financial links to the tobacco industry. Tobacco manufacturers' trade associations were the most prevalent respondents (44/197), followed by non-manufacturing tobaccorelated company trade associations (30/197) (see online supplemental appendix 6 for numbers and percentages for all sectors).

The financial link which the highest number of respondents were found to have was a link to the tobacco industry supply chain (52/131), followed by being an association with tobacco company members (31/131) and an association representing tobacco manufacturers' interests (19/131). Twenty-nine (22.1\%) of the financially linked respondents were not transparent about their links in their consultation submission or linked EU transparency register entries (see online supplemental appendix 7 for complete numbers and percentages of respondents with links and the transparency of these).

\section{TTC membership of trade associations}

Of the 87 trade associations that responded to the consultation, $74(85 \%)$ had a financial link to the tobacco industry, and 19 $(22 \%)$ of these were not transparent. For example, Business Action to Stop Counterfeiting and Piracy, which has a history of lobbying against standardised packaging in Australia and the $\mathrm{EU},{ }^{29}$ made no mention of tobacco companies in its consultation submission or EU transparency register, despite its membership including British American Tobacco (BAT) and Philip Morris International (PMI). ${ }^{30} 31$

Of the 74 trade associations with a financial link, 33 (44.5\%) had TTC members, though this is likely an under-representation as trade association membership is often not publicly available information. Of the 33 where at least one TTC member was identified, British American Tobacco (BAT) was a member of the most trade associations (22) followed by Japan Tobacco International (JTI) (20), PMI (19) and Imperial Tobacco (IT) (17), with considerable overlap in membership. Ten of the trade associations where at least one TTC member was identified did not disclose having any links to the tobacco industry (see online supplemental appendix 8 for list of trade association respondents with TTCs members).

\section{Duplicate policy positions}

The complete answers to the multiple-choice consultation questions of all respondents were compared with those of each of the three TTCs who responded to the consultation (IT, JTI and PMI). Neither IT nor PMI's full multiple-choice answers were exact matches to any other respondent's answers. However, JTI's were found to be exact matches with 38 other respondents, 29 of which were found to have financial links to the tobacco industry (see online supplemental appendix 9 for list of respondents with identical answers to JTI).

\section{Industry-favoured policy positions}

Based on thresholds from existing literature, ${ }^{32}$ there was a very strong association between respondents' answers to questions 1, 3, 4, 17 and 18 and their funding status with $\mathrm{p}$ values under 0.05 and Cramér's V scores above 0.6. There was strong evidence for such an association for questions 2, 15 and 19 with p values under 0.05 and Cramér's V scores above 0.4 (see online supplemental appendix 10 for statistical analysis results for each question).

Of the five questions with the strongest association between respondents' financial link status and their answers, three questions (Q1, Q3 and Q4) relate to the proposed governance model of the EU's track and trace system and two questions (Q17 and Q18) relate to the allowed delays in reporting events (table 2). This indicates a clear policy divide in the policy preferences of respondents with and without a financial link to the tobacco industry on these two issues.

\section{Governance of the T\&T system}

The industry-linked responses showed majority support $(103 / 131)$ for an industry operated system (which would not meet the requirements of the Protocol) and refuted that T\&T is only accomplishable if the supply chain is no longer under tobacco industry control (117/131). Similarly, respondents financially linked to the tobacco industry stated that an industryoperated T\&T solution would be cheaper than one operated by a third party (110/131).

Contrastingly, respondents where no industry link was identified showed a majority preference (39/68) for a third-party operated system and held that T\&T is only achievable under such an approach (46/68). In relation to which system would be most cost-effective, half $(34 / 68)$ of the respondents where no financial link was identified did not express an opinion, while 16/68 of them took the opposite position to that of the majority of industry linked respondents, stating that a third-party operated system would be cheaper (Table 22).

\section{Delays in the reporting of supply chain events}

Question 17 demonstrates a clear preference among respondents with financial links to the tobacco industry for once daily reports (100/131), and no preference between real-time and once weekly reports (both 12/131). Question 18 demonstrates that the majority of respondents with financial links to the 
Table 2 Breakdown of responses to the five questions with strongest association between funding and answers

\begin{tabular}{|c|c|c|c|c|c|c|c|c|}
\hline \multirow[b]{2}{*}{ Question } & \multicolumn{8}{|c|}{ Number of answers and percentages within link/no links groups } \\
\hline & Link & No link & Link & No link & Link & No link & Link & No link \\
\hline \multirow{3}{*}{$\begin{array}{l}\text { Q3: can T\&T only be achieved on condition that the supply chain is } \\
\text { controlled by an independent third party? }\end{array}$} & \multicolumn{2}{|l|}{ Yes } & \multicolumn{2}{|l|}{ No } & \multicolumn{4}{|c|}{ No opinion } \\
\hline & \multirow{2}{*}{\multicolumn{2}{|c|}{$\begin{array}{l}7 \\
5.3 \%\end{array}$}} & \multicolumn{2}{|l|}{117} & 7 & \\
\hline & & & $89.3 \%$ & $\begin{array}{l}19 \\
27.9 \%\end{array}$ & $5.3 \%$ & $4.4 \%$ & & \\
\hline \multirow{3}{*}{$\begin{array}{l}\text { Q18: do you agree that real-time reporting (or limited delays } \\
\text { of maximum several minutes) would be particularly efficient to } \\
\text { track products in transit as it would avoid duplicating scanning } \\
\text { operations? }\end{array}$} & \multicolumn{2}{|l|}{ Yes } & \multicolumn{2}{|l|}{ No } & \multicolumn{4}{|c|}{ No opinion } \\
\hline & \multirow{2}{*}{\multicolumn{2}{|c|}{$\begin{array}{l}9 \\
6.9 \%\end{array}$}} & 109 & & \multicolumn{4}{|l|}{13} \\
\hline & & & $83.2 \%$ & $27.9 \%$ & $9.9 \%$ & $\begin{array}{l}1 \\
1.5 \%\end{array}$ & & \\
\hline \multirow{3}{*}{$\begin{array}{l}\text { Q1: which governance model (industry, third party and mixed) do } \\
\text { you consider most suitable for operating the system? }\end{array}$} & \multicolumn{2}{|c|}{ Industry operated } & \multicolumn{2}{|c|}{ Third party operated } & \multicolumn{2}{|l|}{ Mixed } & \multicolumn{2}{|c|}{ No opinion } \\
\hline & 103 & & 3 & 39 & 16 & & 9 & \\
\hline & $78.6 \%$ & $25.0 \%$ & $2.3 \%$ & $57.4 \%$ & $12.2 \%$ & $\begin{array}{l}7 \\
10.3 \%\end{array}$ & $6.9 \%$ & $7.4 \%$ \\
\hline \multirow{3}{*}{$\begin{array}{l}\text { Q17: which delay in reporting events (real-time/limited delay, } \\
\text { once daily reports and once weekly reports) do you consider most } \\
\text { suitable for operating the system? }\end{array}$} & \multicolumn{2}{|c|}{ Real-time (or limited delay) } & \multicolumn{2}{|c|}{ Once daily reports } & \multicolumn{2}{|c|}{ Once weekly reports } & \multicolumn{2}{|c|}{ No opinion } \\
\hline & 12 & 46 & 100 & 21 & 12 & & 7 & 0 \\
\hline & $9.2 \%$ & $67.6 \%$ & $76.3 \%$ & $30.9 \%$ & $9.2 \%$ & $\begin{array}{l}1 \\
1.5 \%\end{array}$ & $5.3 \%$ & $0.0 \%$ \\
\hline \multirow{3}{*}{$\begin{array}{l}\text { Q4: if an industry and third-party governed system are to be } \\
\text { compared in terms of their overall impact on cost per pack of } \\
\text { product (excluding potential additional monitoring and enforcement } \\
\text { costs for an industry system), which is cheaper? }\end{array}$} & \multicolumn{2}{|c|}{ Industry solution is cheaper } & \multicolumn{2}{|c|}{$\begin{array}{l}\text { Both options have the } \\
\text { same cost impact }\end{array}$} & \multicolumn{2}{|c|}{$\begin{array}{l}\text { Industry solution is more } \\
\text { expensive }\end{array}$} & \multicolumn{2}{|c|}{ No opinion } \\
\hline & 110 & 16 & 2 & 6 & 2 & & 17 & 34 \\
\hline & $84.0 \%$ & $23.5 \%$ & $1.5 \%$ & $8.8 \%$ & $1.5 \%$ & $\begin{array}{l}12 \\
17.6 \%\end{array}$ & $13.0 \%$ & $50.0 \%$ \\
\hline
\end{tabular}

tobacco industry $(109 / 131)$ contested the efficiency of real-time reporting of supply chain events.

Most respondents where a financial link was not identified showed a preference for real-time reporting (46/68), followed by once-daily reports (20/68) and supported the efficiency of real-time reporting (48/68) (Table 2).

\section{DISCUSSION}

\section{Key findings}

This paper's findings outline an extensive lobbying effort on the part of the tobacco industry within the public consultation for the EU's T\&T system. One hundred and thirty-one of the 197 included responses were found to have a financial link to the tobacco industry, with tobacco manufacturer's trade associations (44) and non-manufacturing tobacco-related company trade associations (28) being the most prominent respondent types. Over 20\% (29/131) of the financially linked respondents were not transparent about their links.

In addition to three TTCs submitting individual responses (IT, JTI and PMI), at least one of the four major TTCs were members of 33 trade associations that submitted responses. JTI's exact policy position for each of the consultation's 22 multiple choice questions was matched by 38 other respondents, with 29 of these being financially linked to the industry.

Associations between whether respondents have financial links to the tobacco industry and their policy positions were strongest in relation to questions around the governance model of the system and the allowed delays in the reporting of supply chain events within it. 103 of the industry-linked respondents supported a solution solely governed by the industry and 100 favoured daily reports over real-time reporting of supply chain events. Actors who were not found to have a financial link to the tobacco industry took contrasting stances on both of these issues, showing a clear divide in policy preferences between the two groups.

\section{Limitations}

This research is limited to data that are publicly available, making it possible that some respondents' financial links to the tobacco industry were not identified. While efforts were taken to address language barriers throughout the search process for financial links (including use of translation services and native speakers, where possible), where there was no English-language information available on a respondent, their (potential) financial links to the industry may have been overlooked.

\section{Policy implications and recommendations}

In addition to this consultation, the tobacco industry was given a range of other formal channels to engage the European Commission, such as contributing to a targeted stakeholder consultation $^{33}$ and providing feedback on the draft implementing and delegated acts (the legislation that details how the system should be implemented). ${ }^{29}$ The extensive industry input into the development of the EU's T\&T process is a reflection of the 'Better Regulation' regulatory reforms promoted by the European Commission. ${ }^{30}$ The Better Regulation principles have been criticised for favouring business-friendly policy proposals and were extensively shaped and lobbied for by BAT. ${ }^{31}$ Better Regulation has enabled TTCs to present majority support for policy measures, despite diametrically opposite policy measures being favoured by respondents with no financial links. ${ }^{31}$

In addition to over $20 \%$ of financially linked respondents not disclosing this link in their consultation responses, many respondents did not provide suitable information for any potential links to be identified. This is an issue that the European Commission should resolve by strengthening the EU transparency register's code of conduct to require that organisations fully disclose who their members are and who they hold memberships with. ${ }^{34}$

The EU's T\&T regulations require that, currently, all operators report supply chain events within 24 hours, which was the preferred option for financially linked respondents. Their opposition to real-time reporting of supply chain events likely 
results from the potential increased cost of such a system for actors within the supply chain.

The preference of respondents who are financially linked to the tobacco industry for a T\&T system that is operated solely by the tobacco industry can be viewed as an extension of TTC attempts to undermine the Protocol through promotion of their own T\&T system, Codentify. ${ }^{11}{ }^{35}$ Neither the industry's own T\&T system or any other system that delegates a party's T\&T responsibilities to the tobacco industry can be compliant with the Protocol. ${ }^{36}$

The decision to choose a mixed governance approach (which showed very minimal support in the consultation from both groups) reflects the European Commission's view that a mixed governed system is 'the most balanced approach considering the highly differentiated nature of concerns raised by stakeholders representing divergent interests. ${ }^{37}$ Given the concerns that the EU system may not actually comply with the Protocol, ${ }^{20}$ other parties to the Protocol should not adopt the 'mixed' governance approach to T\&T adopted by the European Commission.

\section{What this paper adds}

What is already known on this subject

- On 20 May 2019, tracking and tracing (T\&T) for cigarettes and roll-your-own tobacco was introduced in the European Union (EU).

- Previous research has demonstrated tobacco industry attempts to influence the EU's T\&T system and the Protocol to Eliminate Illicit Trade in Tobacco Products' envisioned global T\&T regime through prominent use of third parties.

\section{What this paper adds}

- There was an extensive lobbying effort on the part of the tobacco industry over the EU's T\&T system during its public consultation. Transnational tobacco company's (TTC) interests were repeatedly represented through submissions by multiple trade associations.

- Several respondents with financial links to the tobacco industry did not disclose these.

- Collectively, respondents with a financial link to the tobacco industry supported an industry-operated solution that would not have met the requirements of the Protocol to Eliminate Illicit Trade in Tobacco Products. The transparency requirements regarding consultation respondents' affiliations with relevant stakeholders (such as tobacco manufacturers) should be improved for future tobacco-related consultations.

Twitter Allen William Andrew Gallagher @AllenGallagher_and Anna B Gilmore @ BathTR

Acknowledgements We would like to thank Andrew Chapman at the University of Bath for his guidance on statistical analysis and Mercedes Carballo, Kathrin Lauber, Arsenios Tselengidis and Mateusz Zatonski of the Tobacco Control Research Group, University of Bath, for their support in investigating the financial links of respondents where no information was available in English

Contributors AWAG conceived the idea for the study, which was then developed in conjunction with the other authors. AWAG developed the methodology, which was then refined after discussions with the other authors. AWAG collected the data and AWAG and AJ undertook the analysis. AWAG created a draft of the paper, which all authors then contributed to.

Funding $A W A G, K E-R, A J$ and $A B G$ acknowledge the support of Bloomberg Philanthropies Stopping Tobacco Organizations and Products project funding (www. bloomberg.org). KE-R and AJ also acknowledge the support of Cancer Research UK (grant A25745). JH acknowledges the support of Cancer Research UK (Tobacco Advisory Group Award (58487/A22731). AWAG, KE-R, AJ and ABG are part of the
Tobacco Control Research Group, which is a member of the SPECTRUM consortium (Shaping Public Health Policies to Reduce inequalities and harm) funded by the UK Prevention Partnership led by the Medical Research Council (Grant Ref: MR/ SO37519/1)

Disclaimer The opinions expressed are those of the authors alone.

Competing interests None declared.

Patient consent for publication Not required.

Provenance and peer review Not commissioned; externally peer reviewed.

Data availability statement Data are available on reasonable request. Please contact the lead author (a.gallagher@bath.ac.uk) to access underlying data for this research.

Open access This is an open access article distributed in accordance with the Creative Commons Attribution Non Commercial (CC BY-NC 4.0) license, which permits others to distribute, remix, adapt, build upon this work non-commercially, and license their derivative works on different terms, provided the original work is properly cited, appropriate credit is given, any changes made indicated, and the use is non-commercial. See: http://creativecommons.org/licenses/by-nc/4.0/.

\section{ORCID IDs}

Allen William Andrew Gallagher http://orcid.org/0000-0002-3669-0360

Karen Evans-Reeves http://orcid.org/0000-0002-3257-416X

\section{REFERENCES}

1 World Health Organization. World Health Organization Conference of the Parties to the WHO Framework Convention on Tobacco Control.Fifth Session. Seoul. 12-17 November 2012. Decision FCTC/COP 5(1). The Protocol to Eliminate Illicit Trade in Tobacco Products, 2012

2 Joossens L, Raw M. Cigarette smuggling in Europe: who really benefits? Tob Control 1998; 7:66-71

3 WHO FCTCBialous $S$. The tobacco industry and the illicit trade in tobacco products, 2014. Available: http://www.who.int/fctc/publications/The-Tobacco-Industry-and-theIllicit-Trade-in-Tobacco-Products.pdf [Accessed 21 oct 2014].

4 Joossens L, Chaloupka F, Merriman D, et al. Issues in the smuggling of tobacco products. In: Jha P, Chaloupka F, eds. Tobacco control in developing countries. Oxford: Oxford Medical Publications, 2000: 293-406.

5 Nakkash R, Lee K. Smuggling as the "key to a combined market": British American Tobacco in Lebanon. Tob Control 2008;17:324-31.

6 Evans-Reeves KA, Hatchard JL, Gilmore AB. 'It will harm business and increase illicit trade': an evaluation of the relevance, quality and transparency of evidence submitted by transnational tobacco companies to the UK consultation on standardised packaging 2012. Tob Control 2015;24:e168-77.

7 Lee K, Collin J. "Key to the future": British American tobacco and cigarette smuggling in China. PloS Med 2006;3:1080-9.

8 The International Consortium of Investigative Journalists. Global Reach of Tobacco Company's Involvement in Cigarette Smuggling Exposed in Company Papers Washington. The Center for Public Integrity, 2000. Available: https://www. icij.org/investigations/big-tobacco-smuggling/global-reach-tobacco-companysinvolvement-cigarette-smuggling-exposed-company-papers/ [Accessed $06 \mathrm{Nov}$ 2017]

9 Gilmore AB, McKee M. Moving East: how the transnational tobacco industry gained entry to the emerging markets of the former Soviet Union-part II: an overview of priorities and tactics used to establish a manufacturing presence. Tob Control 2004:13:151-60.

10 Collin Jet al. Complicity in contraband: British American tobacco and cigarette smuggling in Asia. Tob Control 2004;13:ii104-11.

11 Gilmore AB, Gallagher AWA, Rowell A. Tobacco industry's elaborate attempts to control a global track and trace system and fundamentally undermine the illicit trade protocol. Tob Control 2019;28:127-40.

12 European Commission. The European system of tobacco traceability and security features operational as of today 20 May 2019. Available: https://ec.europa.eu/health/ sites/health/files/tobacco/docs/20190520_tt_press_en.pdf [Accessed 25 Jun 2019].

13 European Commission. Public consultation on the implementation of an EU system for traceability and security features pursuant to articles 15 and 16 of the tobacco products Directive 2014/40/EU, 2017. Available: https://ec.europa.eu/health/tobacco/ consultations/2016_traceability_security_features_en [Accessed 23 Nov 2017].

14 European Parliament. Council of the European Union. Directive 2014/40/EU of the European Parliament and of the Council of 3 April 2014 on the approximation of the laws, regulations and administrative provisions of the member states concerning the manufacture, presentation and sale of tobacco and related products and repealing Directive 2001/37/EC, 2014

15 Michalopoulos S. Commission hits back at criticism over tobacco track and trace proposal: EURACTIV, 2017. Available: https://web.archive.org/web/20180223012744/ https://www.euractiv.com/section/economy-jobs/news/commission-hits-back-atcriticism-over-tobacco-track-and-trace-proposal/ [Accessed 12 Mar 2019]. 
16 Stevens C. The tobacco Directive: how the European Commission side-lined the European Parliament, 2019. Available: https://web.archive.org/web/20180216234543/ https://www.eureporter.co/health/2018/02/16/the-tobacco-directive-how-theeuropean-commission-side-lined-the-european-parliament/ [Accessed 11 Mar 2019].

17 Stevens C. The EU cracks down on Tobacco, but does it go far enough? : EU Reporter, 2019. Available: https://web.archive.org/web/20190313160733/https://www. eureporter.co/health/2019/01/15/the-eu-cracks-down-on-tobacco-but-does-it-go-farenough/ [Accessed 13 Mar 2019].

18 Stevens C. EP debate: we need to put the REiNS on big tobacco: EU reporter, 2019. Available: https://web.archive.org/web/20190212180412/https://www.eureporter.co/ health/2019/02/01/ep-debate-we-need-to-put-the-reins-on-big-tobacco/ [Accessed 11 Mar 2019].

19 Framework Convention Alliance. Why the EU tracking and tracing system works only for the EU, 2019. Available: https://www.fctc.org/wp-content/uploads/2019/07/FCAPolicy-Briefing_Why-the-EU-tracking-and-tracing-systems-works-only-for-the-EU.pdf [Accessed 28 Aug 2019].

20 Gallagher AWA, Gilmore AB, Eads M. Tracking and tracing the tobacco industry: potential tobacco industry influence over the EU's system for tobacco traceability and security features. Tob Control 2019.

21 International Tax Stamp Association. The relationship between international law and legislative, delegated \& implementing acts of the European Union, 2018. Available: https://www.tax-stamps.org/news-article/the-relationship-between-international-lawand-legislative-delegated-implementing-acts-of-the-european-union [Accessed $29 \mathrm{Apr}$ 2019].

22 InfoCuria. T-396/18 ITSA V Commission, 2019. Available: http://curia.europa.eu/juris/ liste.jsf?oqp $=\& f o r=\& m a t=0 r \& \mid g r e c=e n \& j g e=\& t d=\% 3 B A L L \& j u r=C \% 2 C T \% 2 C F \&$ num $=\mathrm{T}-396 \% 252 \mathrm{~F} 18 \&$ page $=1 \&$ dates $=\& \mathrm{pcs}=0$ or $\& \mathrm{lg}=\& \mathrm{pro}=\&$ nat $=$ or $\& \mathrm{cit}=$ none $\%$ 252CC\%252CCJ\%252CR\%252C2008E\%252C\%252C\%252C\%252C\%252C\% 252C\%252C\%252C\%252C\%252Ctrue\%252Cfalse \%252Cfalse\&language=en\& $\mathrm{avg}=\& \mathrm{cid}=2196007$ [Accessed 10 Sep 2019].

23 Framework Convention Alliance. Update re: FCA's Policy Brief Why the EU tracking and tracing system works only for the EU, 2019. Available: https://www.fctc.org/ update-re-fcas-policy-brief-why-the-eu-tracking-and-tracing-system-works-only-forthe-eu/ [Accessed 10 Oct 2019].

24 Peeters S, Costa H, Stuckler D, et al. The revision of the 2014 European tobacco products directive: an analysis of the tobacco industry's attempts to 'break the health silo'. Tob Control 2016;25:108-17.

25 Tobacco Control Research Group. Third Party techniques. University of Bath, 2017. http://tobaccotactics.org/
26 European Commission. Systems for tobacco traceability and security features undated Available: https://ec.europa.eu/health/tobacco/tracking_tracing_system_en [Accessed 20 Feb 2019].

27 Gallagher AWA, Evans-Reeves KA, Hatchard JL, et al. Tobacco industry data on illicit tobacco trade: a systematic review of existing assessments. Tob Control 2019;28:054295.

28 Hatchard J, Fooks G, Evans-Reeves KA, et al. A critical evaluation of the volume, relevance and quality of evidence submitted by the tobacco industry to oppose standardised packaging of tobacco product. BMJ Open 2014:1-18.

29 European Commission. Public feedback on the draft secondary legislation relating to systems of traceability and security features for tobacco products, as provided for under articles 15 and 16 of Directive 2014/40/EU, 2017. Available: https://ec. europa.eu/health/tobacco/2017_publicfeedback_products_en [Accessed 25 Sep 2017].

30 European Commission. Better regulation: why and how undated. Available: https:// ec.europa.eu/info/law/law-making-process/planning-and-proposing-law/betterregulation-why-and-how_en [Accessed 4 Apr 2019].

31 Tobacco Control Research Group. EU better regulation. University of Bath, 2014. http://tobaccotactics.org/

32 McCormack M, Anderson E, KJamie K, et al. Discovering sociology. London: Palgrave, Macmillan Education, 2018.

33 European Commission. Targeted stakeholder consultation on the implementation of an EU system for traceability and security features pursuant to articles 15 and 16 of the tobacco products Directive 2014/40/EU, 2015. Available: https://ec.europa. eu/health/sites/health/files/tobacco/docs/2015_tpd_c057_en.pdf [Accessed 22 Jan 2018].

34 European Commission. Transparency register: code of conduct Europa. euundated. Available: http://ec.europa.eu/transparencyregister/public/staticPage/ displayStaticPage.do?locale=en\&reference=CODE_OF_CONDUCT [Accessed 10 Oct 2019].

35 Joossens L, Gilmore AB. The transnational tobacco companies' strategy to promote Codentify, their inadequate tracking and tracing standard. Tob Control 2014:23:3-6.

36 World Health Organization. Protocol to eliminate illicit trade in tobacco products, 2013. Available: http://www.who.int/fctc/protocol/illicit_trade/protocol-publication/ en/ [Accessed 21 Jan 2018].

37 European Commission. Inception Impact Assessment, 2016. Available: http://ec europa.eu/smart-regulation/roadmaps/docs/2015_sante_694_695_696_ia_da_tpd_ en.pdf [Accessed 20 Feb 2019]. 